Reduction of regional RV function can occur around the ventriculotomy site after TOF repair. So that postoperative RV function will be preserved, ventriculotomy should be minimal and performed only if necessary.

\section{References}

1. Miura T, Nakano S, Shimazaki Y, Kobayashi J, Hirose H, Sano T, et al. Evaluation of right ventricular function by regional wall motion analysis in patients after correction of tetralogy of Fallot: comparison of transventricular and nontransventricular repairs. J Thorac Cardiovasc Surg. 1992;104:917-23.
2. Sheehan FH, Bolson EL, Dodge HT, Mathey DG, Schofer J, Woo HW. Advantages and applications of the centerline method for characterizing regional ventricular function. Circulation. 1986; 74:293-305.

3. Alexiou C, Chen Q, Galogavrou M, Gnanapragasam J, Salmon AP, Keeton BR, et al. Repair of tetralogy of Fallot in infancy with a transventricular or a transatrial approach. Eur J Cardiothorac Surg. 2002;22:174-83.

4. d'Udekem Y, Ovaert C, Grandjean F, Gerin V, Cailteux M, ShangoLody P, et al. Tetralogy of Fallot: transannular and right ventricular patching equally affect late functional status. Circulation. 2000; 102(Suppl 3):III116-22.

5. Sanchez-Quintana D, Anderson RH, Ho SY. Ventricular myoarchitecture in tetralogy of Fallot. Heart. 1996;76:280-6.

\title{
Cervical ectopic thymoma
}

\author{
I-Lin Hsu, MD, ${ }^{\text {b }}$ Ming-Ho Wu, MD, ${ }^{a}$ Wu-Wei Lai, MD, ${ }^{a}$ Mu-Yen Lin, MD, ${ }^{a}$ Jia-Ming Chang, MD, ${ }^{a}$ Yi-Ting Yen, MD, and \\ Yau-Lin Tseng, MD, ${ }^{a}$ Tainan, Taiwan
}

T

he thymus develops from the third and fourth brachial clefts and descends into the anterior mediastinum by the sixth week of gestation. Thymic ectopia results from hypoplasia, failure of descent, and dislocation of thymus along the path of descent. ${ }^{1}$ Cervical ectopic thymoma is extremely rare, and only 23 cases were reported until 2005 . $^{2}$ Most cases occur in women and generally present with a mass in the neck, often confused clinically with a thyroid nodule. Preoperative diagnosis is difficult even with aspiration biopsy. We present 2 patients with cervical ectopic thymoma; one is type $\mathrm{AB}$ and the other is type $\mathrm{C}$ (thymic carcinoma).

\section{Clinical Summaries}

CASE 1: A 55-year-old woman had a palpable neck mass for 20 years. She visited the General Surgery department because of recent dyspnea. Chest radiograph revealed cervical tracheal deviation by tumor compression. The echo with color Doppler showed a 7-cm heterogeneous, hypoechoic, and hypervascular tumor in the suprasternal notch; the thyroid gland was of normal size and echo pattern. Computed tomography revealed a large neck mass adhering to the thyroid with external compression of

\footnotetext{
From the Departments of Surgery ${ }^{\mathrm{a}}$ and Emergency, ${ }^{\mathrm{b}}$ Division of Thoracic Surgery, National Cheng Kung University Hospital, Tainan, Taiwan.

Received for publication Nov 30, 2006; accepted for publication Jan 23, 2007.

Address for reprints: Yau-Lin Tseng, Division of Thoracic Surgery, Department of Surgery, National Cheng Kung University Hospital, Tainan, Taiwan. (E-mail: tsengyl@mail.ncku.edu.tw).

J Thorac Cardiovasc Surg 2007;133:1658-9

$0022-5223 / \$ 32.00$

Copyright (C) 2007 by The American Association for Thoracic Surgery doi:10.1016/j.jtcvs.2007.01.037
}

the cervical trachea (Figure 1, $A$ and $B$ ). We performed tumor resection and thymectomy. The yellowish encapsulated tumor, measuring $7.0 \times 5.5 \times 3.0 \mathrm{~cm}$, was beneath the thyroid gland, without contact. Pathology revealed that it was a stage I type AB thymoma. Postoperative recovery was good, and there has been no recurrence after follow-up of 7 months

CASE 2: A 49-year-old man had hoarseness for 3 months. He visited an ear, nose, and throat clinic where left vocal cord palsy and a $3 \times 2 \mathrm{~cm}$ palpable mass on the neck were found. Chest radiograph revealed a mass on the lower neck with compressive deviation of the trachea. Computed tomography showed a neck mass, lateral to the cervical trachea, near the lower pole of left thyroid with recurrent laryngeal nerve and esophageal involvement (Figure 2, $A$ and $B$ ). He was referred to our department for further management. Bronchoscopy and esophagoscopy revealed that there was no intraluminal invasion of tumor. After discussion with the patient, on the lower neck a T-shape incision was performed to resect the tumor and obtain final diagnosis. En bloc resection was performed and included partial thyroidectomy, tumor resection, sacrifice of nonfunctional left recurrent laryngeal nerve, partial resection of muscular layer of esophagus, and left neck lymph node dissection. Frozen section of the mass showed a squamous cell carcinoma, which was CD5 positive on an immunohistochemical stain and invaded surrounding adipose tissue and muscular layer of the esophagus. Thymectomy was then performed. Final pathology revealed that in addition to the main $4.6 \times 4.2 \mathrm{~cm}$ tumor on the neck, there was a small $0.15-\mathrm{cm}$ thymic carcinoma in the remnant mediastinal thymus. One of 8 cervical lymph nodes was metastatic. The thyroid was adhered to the tumor but was not invaded. The patient was discharged uneventfully 1 week after operation. Postoperative chemotherapy (carboplatin, ifosfamide, and 5-fluorouracil) was given for 3 courses followed by mediastinal and neck 4500 cGy of radiotherapy. He was well without recurrence at 26-month follow-up. 


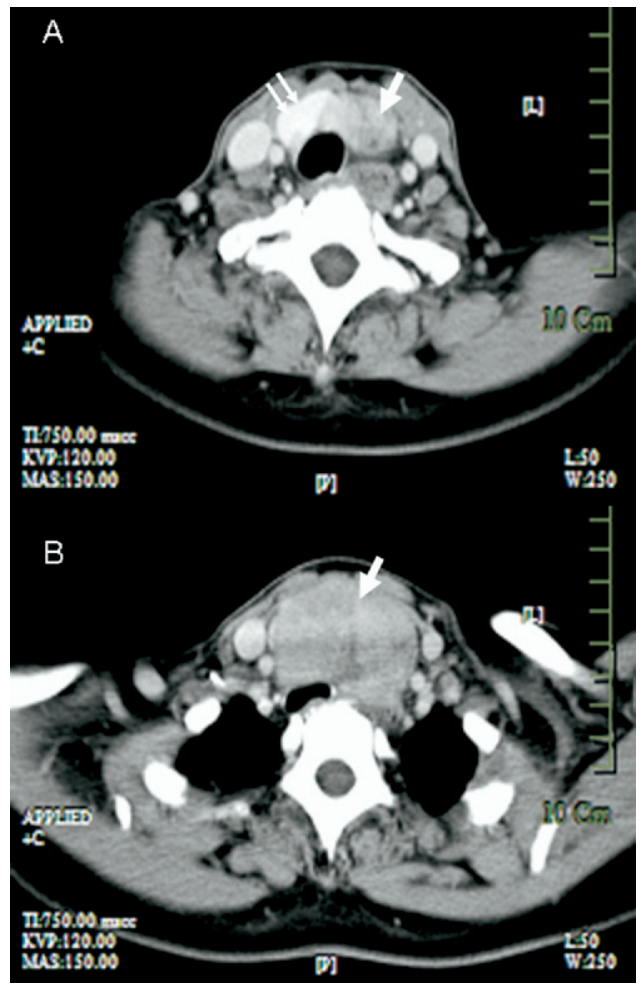

Figure 1. Computed tomographic scan of the neck shows (A) a tumor mass (arrow) adhered to the thyroid (double arrow) and (B) external compression of the cervical trachea by tumor (arrow).

\section{Discussion}

The differential diagnosis between thyroid nodule and cervical thymic tumor was made by thyroid sonography, position of the tumor at the computed tomography or perioperative evaluation, and its total individualization from the thyroid. The preoperative diagnosis of cervical thymic tumor is difficult, although some investigation techniques are used, such as aspiration biopsy, scintigraphy with thallium 201 or technetium 99, and radioactive iodine. $^{3}$

In the mediastinum, type $\mathrm{AB}$ thymoma is always benign in nature and resected in an early stage, whereas thymic carcinoma is very invasive and usually diagnosed at a late stage. From our experience and the literature review, cervical thymoma and thymic carcinoma seem to have the same tumor behavior as they do in the mediastinum. ${ }^{4}$ The tumor in case 1 was still well encapsulated and did not invade the trachea, which had been compressed by it for more than 20 years. In case 2 , although the tumor was small, it was locally advanced. In addition, there was a synchronous small thymic carcinoma noted microscopically in the remnant of resected mediastinal thymus. This variety of tumor behavior may



Figure 2. Computed tomographic scan of the neck shows $(A)$ a tumor (arrow) near the thyroid (double arrow) and (B) involvement of recurrent laryngeal nerve and esophagus (double arrow) by tumor (arrow).

help us to differentiate cervical thymoma or thymic carcinoma preoperatively.

The importance of concomitant thymectomy for treating ectopic cervical thymic tumor is rarely discussed in the literature. From our experience with patient 2 in this report, thymectomy may be mandatory during resection of ectopic thymic carcinoma.

\section{References}

1. Rosai J, Levine GD. Tumors of the Thymus. In: Atlas of Tumor Pathology, 2nd Series, Fascicle 13. Washington, DC: Armed Forces Institute of Pathology, 1976;1: p. 151-3.

2. Chang ST, Chuang SS. Ectopic cervical thymoma: a mimic of T-lymphoblastic lymphoma. Pathol Res Pract. 2003;199:633-5.

3. Ponder TB, Collins BT, Bee CS, Silverberg AB, Grosso LE, Dunphy $\mathrm{CH}$. Diagnosis of cervical thymoma by fine needle aspiration biopsy with flow cytometry. A case report. Acta Cytol. 2002;46: 1129-32.

4. Tan A, Holdener GP, Hecht A, Gelfand C, Baker B. Malignant thymoma in an ectopic thymus. CT appearance. J Comput Assist Tomogr. $1991 ; 15: 842-4$ 